\title{
Enhanced Intermediate-Temperature Electrochemical Performance of Air Electrodes for Solid Oxide Cells with Spray-Pyrolysed Active Layers
}

\author{
Víctor Zapata-Ramírez ${ }^{1}$, Lucía dos Santos-Gómez ${ }^{2}$, Glenn C. Mather ${ }^{1}$, \\ David Marrero-López ${ }^{3}$, Domingo Pérez-Coll ${ }^{1, *}$ \\ ${ }^{1}$ Instituto de Cerámica y Vidrio, CSIC, Campus de Cantoblanco, 28049 Madrid, Spain \\ ${ }^{2}$ Universidad de Málaga, Departamento de Química Inorgánica, 29071 Málaga, Spain \\ ${ }^{3}$ Universidad de Málaga, Departamento de Física Aplicada I, 29071 Málaga, Spain
}

\begin{abstract}
The potential of interactive layers of mixed-conducting oxides for improving the performance of air electrodes of solid oxide cells in the intermediate temperature range is demonstrated. Active layers of $\mathrm{Ce}_{0.9} \mathrm{Gd}_{0.1} \mathrm{O}_{2-\delta}$ (CGO), $\mathrm{Ce}_{0.8} \operatorname{Pr}_{0.2} \mathrm{O}_{2-\delta}$ (CPO) and $\mathrm{SrFe}_{0.9} \mathrm{Mo}_{0.1} \mathrm{O}_{3-\delta}(\mathrm{SFM})$ with thickness in the range 200-400 $\mathrm{nm}$ are deposited on CGObased electrolyte by spray pyrolysis, followed by deposition of a SFM/CGO composite air electrode by painting. The morphologies and phase composition of the active layers are examined by X-ray diffraction, scanning electron microscopy and energy-dispersive $\mathrm{X}$-ray spectroscopy microanalysis. The electrochemical performance of the electrolyteelectrode assemblies is determined by impedance spectroscopy in the range $600-800{ }^{\circ} \mathrm{C}$. Significant improvement in the performance of the electrode process and the geometrically-normalized ohmic conductance are observed for the assembly with CPO active layer with mixed oxide-ionic-electronic conductivity, especially in the low temperature range, attributable to extension of the surface path of the electrochemical reactions. The CGO intermediate layer also improves performance but to a lesser degree, most likely due to better ionic-current collection in comparison to the assemblies with either SFM as active layer or no active layer.
\end{abstract}

Keywords: spray pyrolysis; active interlayers; SOFC; cathode; mixed conducting properties; surface path 


\section{Introduction}

The production of hydrogen through electrolysis of water using sustainably generated electricity and its reconversion into electricity by fuel cells is expected to form a significant portion of the renewable-energy portfolio. The thermodynamics of fuel combustion and fuel flexibility are more favourable at high temperature. Accordingly, there is considerable commercial and research interest in solid oxide fuel cells (SOFCs) composed of a ceramic electrolyte, porous ceramic cathode and porous cermet anode with an operating temperature above $500{ }^{\circ} \mathrm{C}^{1}$. Operation of such ceramic cells in reversible mode (electrolysis) is also more thermodynamically suitable than low-temperature electrolysis ${ }^{2}$. An intermediate temperature range $\left(500-800{ }^{\circ} \mathrm{C}\right)$, for both modes of operation, reduces the material degradation, increases lifetimes, shortens start-up and shutdown times, and permits the use of cheaper balance-of-plant materials (e.g. stainless steel below $\left.600{ }^{\circ} \mathrm{C}\right)^{3}$.

The development of solid oxide cells requires good electrode performance in both fuel cell and electrolyser modes, placing particularly strict requirements on the electrode characteristics. The air electrode performance is especially relevant in the intermediate temperature range, where the kinetics of the oxygen electrochemical reactions are slower. We have recently studied the effects of Mo doping in $\mathrm{SrFeO}_{3-\delta}$ perovskite, finding that the electrochemical performance under both cathodic and anodic polarization of $\mathrm{SrFe}_{0.9} \mathrm{Mo}_{0.1} \mathrm{O}_{3-\delta}$ is promising for use as air electrode in reversible solid oxide cells and very competitive with the cobalt-containing material, $\mathrm{SrFe}_{0.45} \mathrm{Co}_{0.45} \mathrm{Mo}_{0.1} \mathrm{O}_{3-\delta}$, but with more compatible thermal expansion with other cell components ${ }^{4}$. Similar ferrite-based perovskites are also of interest in symmetrical SOFCs, where switching polarity provides a solution to coke formation and sulphur poisoning of the anode on operation with hydrocarbons, since the pollutant species may be reoxidised ${ }^{5,6}$.

Many promising perovskite air electrodes exhibit high activation energies for the oxygen oxidation-reduction reaction $^{7,8}$, resulting in considerable electrode polarisation resistance as temperature decreases. This has encouraged the adoption of different strategies for improving the electrode performance at intermediate temperature ${ }^{9}$. Many of these approaches are focused on the implementation of nanometric morphologies in order to increase the number of active reaction sites, leading to a decrease of the working temperature in $\mathrm{SOFCs}^{10}$. Examples include the modification of the active surface of a 
porous scaffold by infiltration of active species to improve the cathode performance ${ }^{11}$, and the use of advanced nanostructured electrodes based on nanotubes ${ }^{12}$ or nanofibers ${ }^{13}$, which were demonstrated to greatly facilitate mass- and charge-transfer processes. Further routes include the fabrication of mesoporous materials, with high surface area for electrochemical reaction ${ }^{13}$, core-shell structures with an enhanced performance associated with a very good interconnection between the shell and the matrix ${ }^{8}$, or the incorporation of thin films with nanometric grain size and very high surface area ${ }^{14}$. In particular, interest in the incorporation of thin layers with different morphologies has grown considerably due to the increasing use of advanced deposition technologies ${ }^{9}$. For example, pulsed laser deposition (PLD) was employed to demonstrate that $\mathrm{La}_{0.8} \mathrm{Sr}_{0.2} \mathrm{CoO}_{3-\delta}$ epitaxial thin films present better electrochemical activity for oxygen reduction in comparison to the bulk material, due to a higher oxygen vacancy content in the films ${ }^{15}$. Moreover, Januschewsky et al. ${ }^{16}$ found that $\mathrm{La}_{0.8} \mathrm{Sr}_{0.2} \mathrm{CoO}_{3-\delta}$ thin films prepared by PLD improved the performance as the deposition temperature decreased, suggesting that the surface of the amorphous cathode could be highly active for oxygen incorporation. Magnetron sputtering was also successfully used for deposition of thin film cathodes, such as $\mathrm{Ln}_{2} \mathrm{NiO}_{4}(\mathrm{Ln}=\mathrm{La}, \mathrm{Pr}, \mathrm{Nd})^{17}$, or nanoscaled interlayers based on $\mathrm{La}_{0.6} \mathrm{Sr}_{0.4} \mathrm{CoO}_{3-\delta}{ }^{18}$ and $\mathrm{La}_{0.6} \mathrm{Sr}_{0.4} \mathrm{Co}_{0.2} \mathrm{Fe}_{0.8} \mathrm{O}_{3-\delta}{ }^{19}$, resulting in improved fuel-cell performance. In this regard, graded electrodes, which include more than a single layer, have attracted much interest recently due to the possibility of combining several functionalities, which may improve the electrochemical performance ${ }^{20}$. Graded cathodes, based on the incorporation of an intermediate dense layer of $\mathrm{La}_{2} \mathrm{NiO}_{4+\delta}$ between a porous $\mathrm{La}_{2} \mathrm{NiO}_{4+\delta}$ electrode and a dense YSZ electrolyte with CGO interlayer, improved the electrode kinetics due to better oxide ion transfer between the electrode and the electrolyte, associated with an improved contact at the boundary layer ${ }^{21,22}$. Similarly, a thin, dense layer of the same composition as the cathode $\left(\operatorname{PrBa}_{0.5} \operatorname{Sr}_{0.5} \mathrm{Co}_{1.5} \mathrm{Fe}_{0.5} \mathrm{O}_{5+\delta}\right)$, deposited between the electrolyte and cathode, improves the performance of protonic ceramic fuel cells through decreasing the contact resistance ${ }^{23}$. Moreover, a multilaminated composite cathode based on alternating porous layers of $\mathrm{La}_{0.6} \mathrm{Sr}_{0.4} \mathrm{Co}_{0.2} \mathrm{Fe}_{0.8} \mathrm{O}_{3-\delta}$ and $\mathrm{Ce}_{0.9} \mathrm{Gd}_{0.1} \mathrm{O}_{1.95}$, was reported to improve the oxygen reduction activity due to an extended three-phase boundary (TPB $)^{24}$.

Previous studies have also revealed that the introduction of a minor p-type electronconducting component in the electrolyte can significantly increase the electrochemically 
active region for oxygen exchange at the air electrode-electrolyte interface, thereby minimising losses associated with interfacial polarisation ${ }^{25-27}$. An alternative explanation to the extended active region for the enhancement in kinetics, suggested by Adler ${ }^{7}$, focuses on improvement of the existing rate process close to the TPB. Nevertheless, buffer layers with multivalent cations deposited between YSZ electrolyte and $\mathrm{Nd}_{2} \mathrm{NiO}_{4+\delta}$ electrode by spin coating proved highly effective for ameliorating the electrochemical behaviour in air, supporting the hypothesis of an extension of the active surface reaction ${ }^{28}$. These results highlight the promising new concept of tailoring the mixed transport properties of buffer or active layers as a strategy to improve the kinetics of air electrodes for intermediate temperature electrochemical devices through increasing the active reaction surface.

In the present study, spray pyrolysis was employed for the introduction of active layers between the electrolyte and cathode. This deposition technique is both economic and industrially scalable, and has been demonstrated to be efficient for the deposition of SOFC and micro-SOFC components ${ }^{29,30}$. Thin gas-tight or porous layers may be achieved with the possibility of producing graduated layers, multilayers and buffer layers, as recently shown for the deposition of CGO protective layers between YSZ electrolyte and LSCF cathode ${ }^{24,31}$. In addition, the layers may be deposited in a single step and the fabrication temperature reduced, minimising the reaction between cell components. Here, we explore the strategy of depositing thin films with different mixed-conduction properties between an $\mathrm{SrFe}_{0.9} \mathrm{Mo}_{0.1} \mathrm{O}_{3-\delta}$ air electrode and a CGO-based electrolyte doped with $\mathrm{Co} . \mathrm{SrFe}_{0.9} \mathrm{Mo}_{0.1} \mathrm{O}_{3-\delta}$ synthesized by a freeze-drying precursor route is prepared as a composite with CGO and deposited on the active layers by a conventional deposition method. The microstructures and electrochemical properties are measured to compare the performances of the assemblies with different active-layer compositions and with no active layer. 


\section{Experimental}

Ceria-based electrolytes were obtained from commercial powders of $\mathrm{Ce}_{0.9} \mathrm{Gd}_{0.1} \mathrm{O}_{2-\delta}$ (CGO, Rhodia). The densification of CGO was enhanced on adding an ethanol solution with 2 mol.\% $\mathrm{Co}\left(\mathrm{NO}_{3}\right)_{2} \cdot 6 \mathrm{H}_{2} \mathrm{O}$ to $\mathrm{CGO}$ powders (CGO2Co) and milling until dry, calcining at $650{ }^{\circ} \mathrm{C}$ for 1 hour, uniaxially pressing into pellets and sintering at $1100{ }^{\circ} \mathrm{C}$ for 6 hours, resulting in cylindrical samples of $\sim 8 \mathrm{~mm}$ in diameter and $\sim 1 \mathrm{~mm}$ in thickness. This level of Co dopant was chosen since it is an ideal content to improve the sinterability and grain-boundary conductivity of the electrolyte, and reduce the airelectrode polarization resistance through enhancement of the minor p-type electronic conductivity of the ceria-based electrolyte ${ }^{25,26}$.

Aqueous precursor solutions for symmetrical deposition of active layers by spray pyrolysis were prepared for the compositions $\mathrm{Ce}_{0.9} \mathrm{Gd}_{0.1} \mathrm{O}_{2-\delta}, \mathrm{Ce}_{0.8} \operatorname{Pr}_{0.2} \mathrm{O}_{2-\delta}(\mathrm{CPO})$ and $\mathrm{SrFe}_{0.9} \mathrm{Moo}_{0.1} \mathrm{O}_{3-\delta}(\mathrm{SFM})$ from the corresponding reagents of the constituent cations: $\mathrm{Ln}\left(\mathrm{NO}_{3}\right)_{3} \cdot 6 \mathrm{H}_{2} \mathrm{O}(\mathrm{Ln}=\mathrm{Ce}, \mathrm{Gd}, \mathrm{Pr}), \mathrm{Sr}\left(\mathrm{NO}_{3}\right)_{2}, \mathrm{Fe}\left(\mathrm{NO}_{3}\right)_{3} \cdot 9 \mathrm{H}_{2} \mathrm{O}, \mathrm{MoO}_{3}$ (all Sigma-Aldrich, purity>99\%) and Ethylenediaminetetraacetic acid (EDTA) as chelating agent to avoid phase segregation (1:1 EDTA:metal ratio). The precursor solutions with a concentration $0.02 \mathrm{~mol} \mathrm{~L}^{-1}$ were sprayed onto the CGO2Co membranes at $450{ }^{\circ} \mathrm{C}$ with a solution flow rate of $20 \mathrm{ml} \mathrm{h}^{-1}$ and a pressure of 2 bar; nozzle-substrate distance and deposition time were $20 \mathrm{~cm}$ and $30 \mathrm{~min}$, respectively. The electrolyte/active-layer assemblies were then treated at $800{ }^{\circ} \mathrm{C}$ for 1 hour to remove residual organic species and obtain the final singlephase material.

Powder cathode material of $\mathrm{SrFe}_{0.9} \mathrm{Mo}_{0.1} \mathrm{O}_{3-\delta}$ was prepared by a freeze-drying precursor method from a stoichiometric aqueous cation solution of the metal nitrates with ethylenediaminetetraacetic acid (EDTA) as chelating agent in a ligand:metal ratio of 1:1, following a methodology reported elsewhere ${ }^{6}$. In brief, the obtained solution was dropped into liquid nitrogen and the frozen material was dehydrated by vacuum sublimation in a Telstar Cryodos freeze-drier for 2 days. Dried powders were initially fired at $300{ }^{\circ} \mathrm{C}$ for 1 hour to decompose the organic matter, followed by a second thermal treatment at 800 ${ }^{\circ} \mathrm{C}$ for 1 hour to achieve crystallisation and obtain single-phase materials.

The SFM powder was then ball milled with CGO in the mass ratio SFM:CGO 70:30 and made into a suspension on mixing with Decoflux ${ }^{\mathrm{TM}}$ (WB41, Zschimmer and Schwarz) as 
organic binder. The resulting ink was symmetrically painted on top of the active layers or directly on top of CGO2Co substrate, followed by sintering at $1000{ }^{\circ} \mathrm{C}$ for 1 hour.

Completeness of reaction and phase purity of the prepared materials were determined by powder X-ray diffraction (XRD) with a PANalytical Empyrean diffractometer using $\mathrm{CuK} \alpha$ radiation. Grazing incidence XRD was employed for the analysis of active layers deposited over CGO2Co electrolytes by spray pyrolysis. Phase identification and analysis were performed using the X'Pert HighScore Plus and either FullProf ${ }^{32}$ or GSAS software $^{33}$. Microstructure and cation interdiffusion at the interfaces between the CGO and active layer, and active layer and SFM:CGO cathode, were analysed by Field Emission Scanning Electron Microscopy (FE-SEM) with a Helios Nanolab 650 instrument coupled with energy-dispersive X-ray microanalysis (EDX, Oxford Instruments).

The half-cell assemblies were prepared for impedance-spectroscopy measurements on coating the SFM/CGO cathode surface with Pt paste and firing at $800{ }^{\circ} \mathrm{C}$ for 1 hour. Impedance spectra were collected with an Autolab PGSTAT302N-FRA2 instrument, operating in the frequency range $10^{-1} \leq \mathrm{f} \leq 10^{6} \mathrm{~Hz}$ with an excitation voltage of $0.05 \mathrm{~V}$. Samples were measured in the range $600-800{ }^{\circ} \mathrm{C}$ on cooling in steps of $50{ }^{\circ} \mathrm{C}$ in air with a dwell time of $30 \mathrm{~min}$ at each temperature. Analysis of impedance spectra was performed with the ZView 2.9c software (Scribner associates) by fitting the data to appropriate equivalent circuits to resolve the contributions of the ohmic transport and electrochemical processes according to their capacitances.

\section{Results and Discussion}

\subsection{Phase Analysis}

The XRD powder pattern of SFM synthesized by freeze-drying, followed by sintering at $800{ }^{\circ} \mathrm{C}$, indicated the formation of a single-phase perovskite material (Fig. 1(a)). The oxygen-ordered $\mathrm{SrFeO}_{3-\delta}$ composition ${ }^{6,34}$ is stabilized as a cubic perovskite (space group, $P m \overline{3} m$ ) at the resolution of the diffracting medium on partial substitution of Fe for Mo, as previously reported ${ }^{4,35}$. An XRD powder pattern of the SFM:CGO composite air electrode fired at $800{ }^{\circ} \mathrm{C}$ for 12 hours is shown in Fig. 1(b). The only reflections present are those corresponding to SFM and CGO, indicating that the air-electrode components do not react to any significant extent at the sintering temperature. It is inferred that 
reaction with the CGO electrolyte is not expected to occur at temperatures lower than $1100{ }^{\circ} \mathrm{C}$, in agreement with previous results ${ }^{36}$.
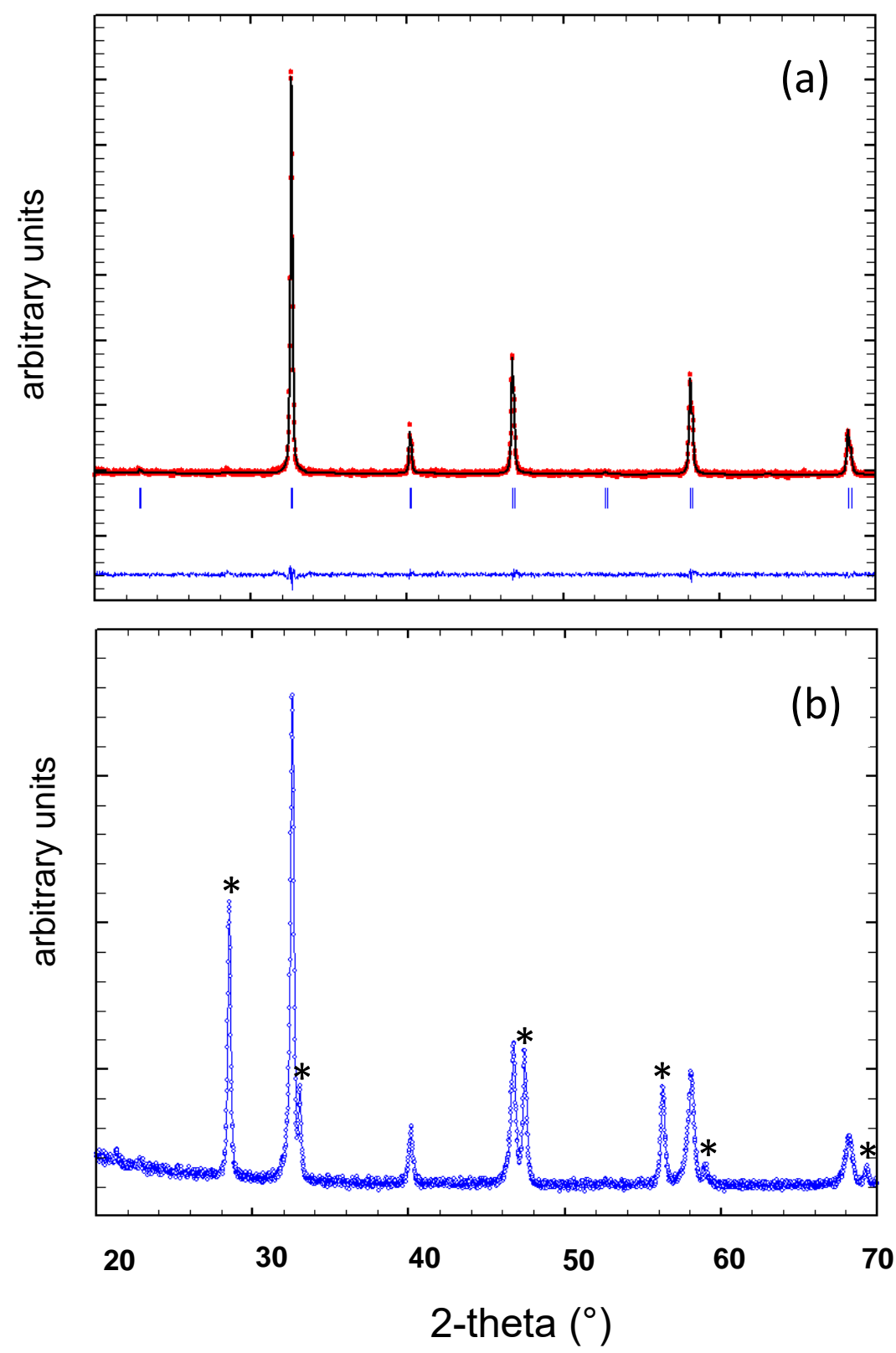

Fig. 1. (a) XRD Rietveld plot of $\mathrm{SrFe}_{0.9} \mathrm{Mo}_{0.1} \mathrm{O}_{3-\delta}$ prepared by freeze-drying and heated at $800{ }^{\circ} \mathrm{C}$ for 4 hours. Experimental data (red circles), calculated (continuous black line) and difference (continuous blue line at bottom of panel). (b) XRD pattern of a SFM:CGO (70:30) powder mixture heated at $800{ }^{\circ} \mathrm{C}$ for 12 hours. Peaks marked with an asterisk correspond to CGO; unmarked peaks correspond to $\mathrm{SrFe}_{0.9} \mathrm{Mo}_{0.1} \mathrm{O}_{3-\delta}$. 
The XRD pattern of SFM active layer prepared by spray pyrolysis on CGO2Co electrolyte followed by sintering at $800{ }^{\circ} \mathrm{C}$, Fig. 2(a), consists of the diffraction peaks of the SFM and CGO phases, assigned to the active layer and substrate, respectively.

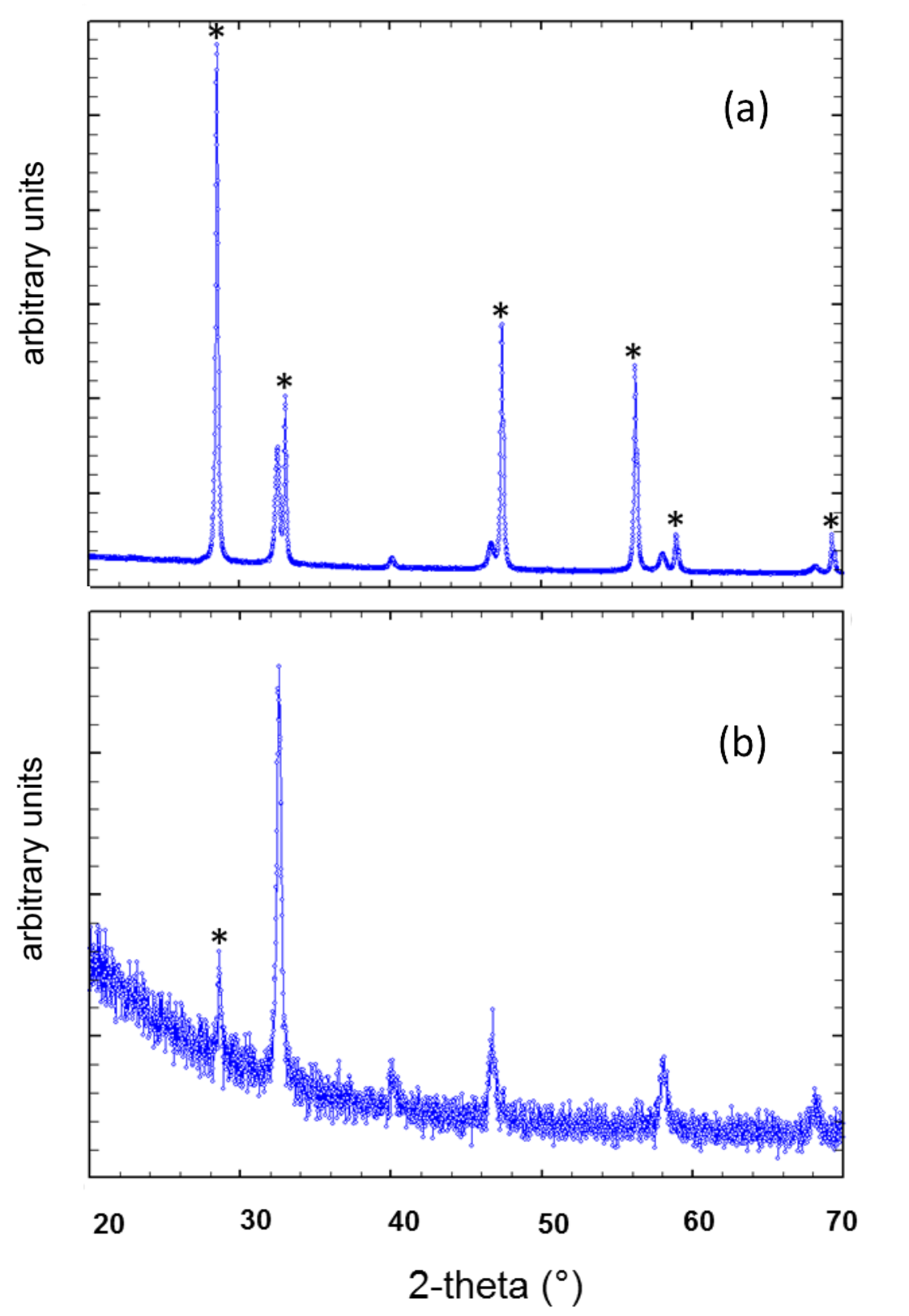

Fig. 2. (a) XRD pattern of SFM active layer prepared and deposited on CGO2Co electrolyte by spray pyrolysis, followed by sintering at $800{ }^{\circ} \mathrm{C}$ and (b) the corresponding grazing incidence XRD pattern. Peaks marked with an asterisk correspond to CGO substrate; unmarked peaks correspond to SFM active layer.

The corresponding grazing incidence XRD pattern (Fig. 2(b)) is dominated by the diffraction peaks of the SFM layer, and only the most intense peak of the CGO2Co 
substrate is observed. The similar diffraction patterns of the CGO and CPO layers with respect to $\mathrm{CGO} 2 \mathrm{Co}$ electrolyte avoids the identification of the phases corresponding to the films. However, the presence of any secondary phase associated with Gd and Pr oxide segregations is not apparent, indicating that the fluorite films are phase pure.

\subsection{Microstructural characterisation}

A series of cross-sectional micrographs of half-cell air-electrode/active layer/electrolyte assemblies consisting of CGO2Co electrolyte and SFM:CGO air electrode with SFM, CGO and CPO interlayers, deposited by spray pyrolysis between the electrode and the electrolyte (SFM(SP), CGO(SP) and CPO(SP)), are shown in Figs. 3-5.

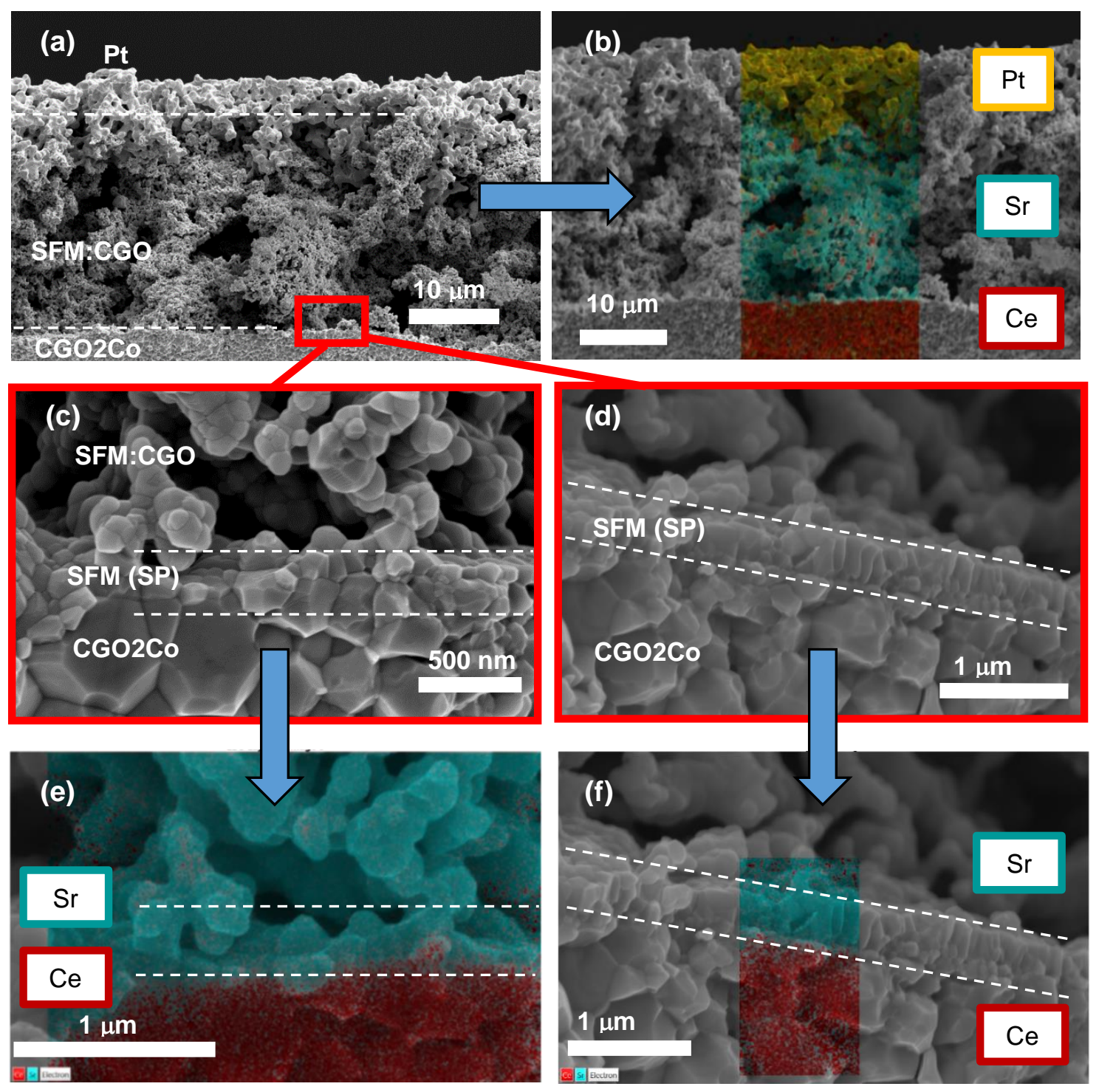

Fig. 3. SEM images of SFM:CGO/SFM(SP)/CGO2Co assemblies: (a) general transversal view; (b) EDXS mapping corresponding to $\mathrm{Ce}, \mathrm{Sr}$ and Pt elements of (a); (c) and (d) 
higher magnification images of SFM:CGO/SFM(SP)/CGO2Co interfaces; (e) and (f) EDXS analysis of Sr and Ce elements at the interfaces.

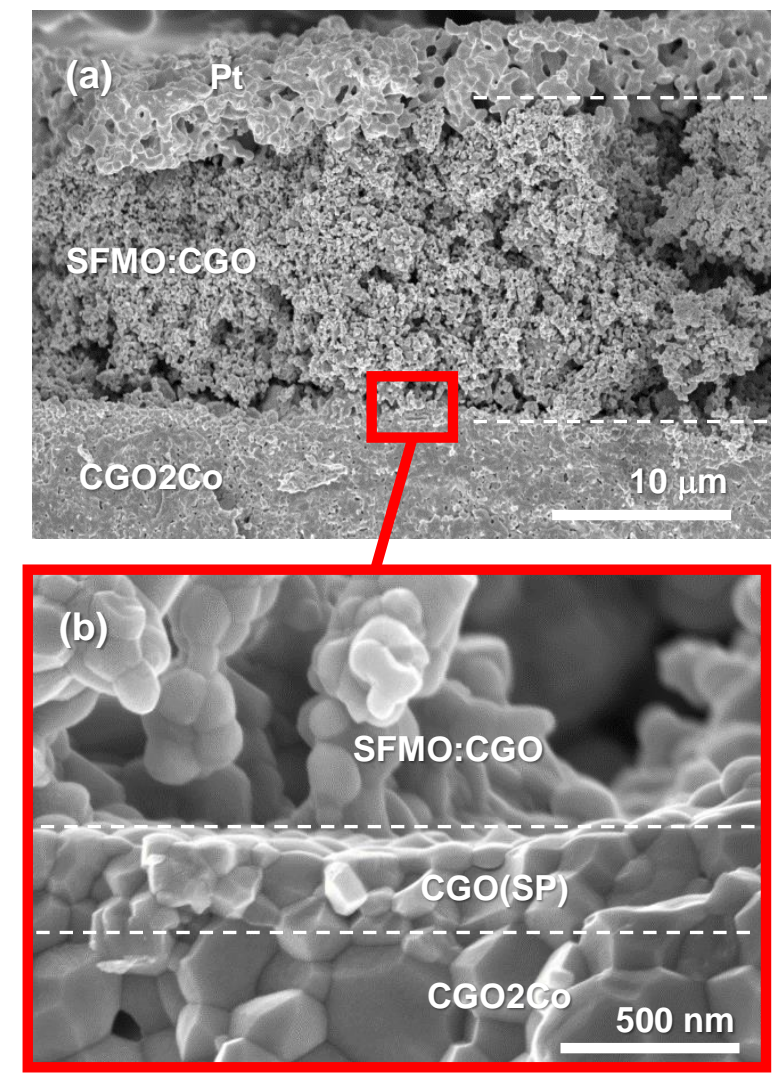

Fig. 4. SEM images of SFM:CGO/CGO(SP)/CGO2Co assemblies: (a) general transversal view; (b) higher magnification image of the interfaces between electrolyte (CGO2Co), active layer (CGO(SP)) and air electrode (SFM:CGO).

The micrographs confirm the high porosity, good homogeneity and grain size $\sim 200 \mathrm{~nm}$ for SFM:CGO composite, as well as high densification of the electrolyte in the three studied configurations. The grain size of the electrolyte is retained in the range of $\sim 500$ $\mathrm{nm}$, due to the low sintering temperature achieved on addition of $2 \mathrm{~mol} \% \mathrm{Co}$ as sintering aid, which improves mechanical stability, the electrolyte grain-boundary conductivity and the electrochemical performance of the air electrode-electrolyte interface ${ }^{26,37}$. The SFM (Fig. 3), CGO (Fig. 4) and CPO (Fig. 5) interlayers, prepared by spray pyrolysis, are dense with a thickness in the range $200-400 \mathrm{~nm}$ and exhibit excellent adhesion to the CGO2Co electrolyte. EDX analysis, performed on the SFM:CGO/SFM(SP)/CGO2Co assembly for Sr and Ce cations (Figs. 3b, e and f), reveals that the layers are apparently well defined, suggesting adequate chemical compatibility. However, minor migration of Sr species from the SFM component to the CGO-based electrolyte is inferred, as reported earlier for 
other Sr-based compositions, such as LSCF, which is expected to be mainly promoted by diffusion through grain boundaries. ${ }^{31,38,39}$ Moreover, the Pt current collector in contact with the SFM:CGO composite is clearly defined without any apparent penetration into the bulk of the active component. The interactive layers are dense with a distinct microstructure to that of the electrolyte due to the low sintering temperature $\left(800{ }^{\circ} \mathrm{C}\right)$. Moreover, no cracks or discontinuities are observed, which renders the interlayer a good transition component between the CGO2Co electrolyte and the SFM:CGO electrode (Figs. 3-5).
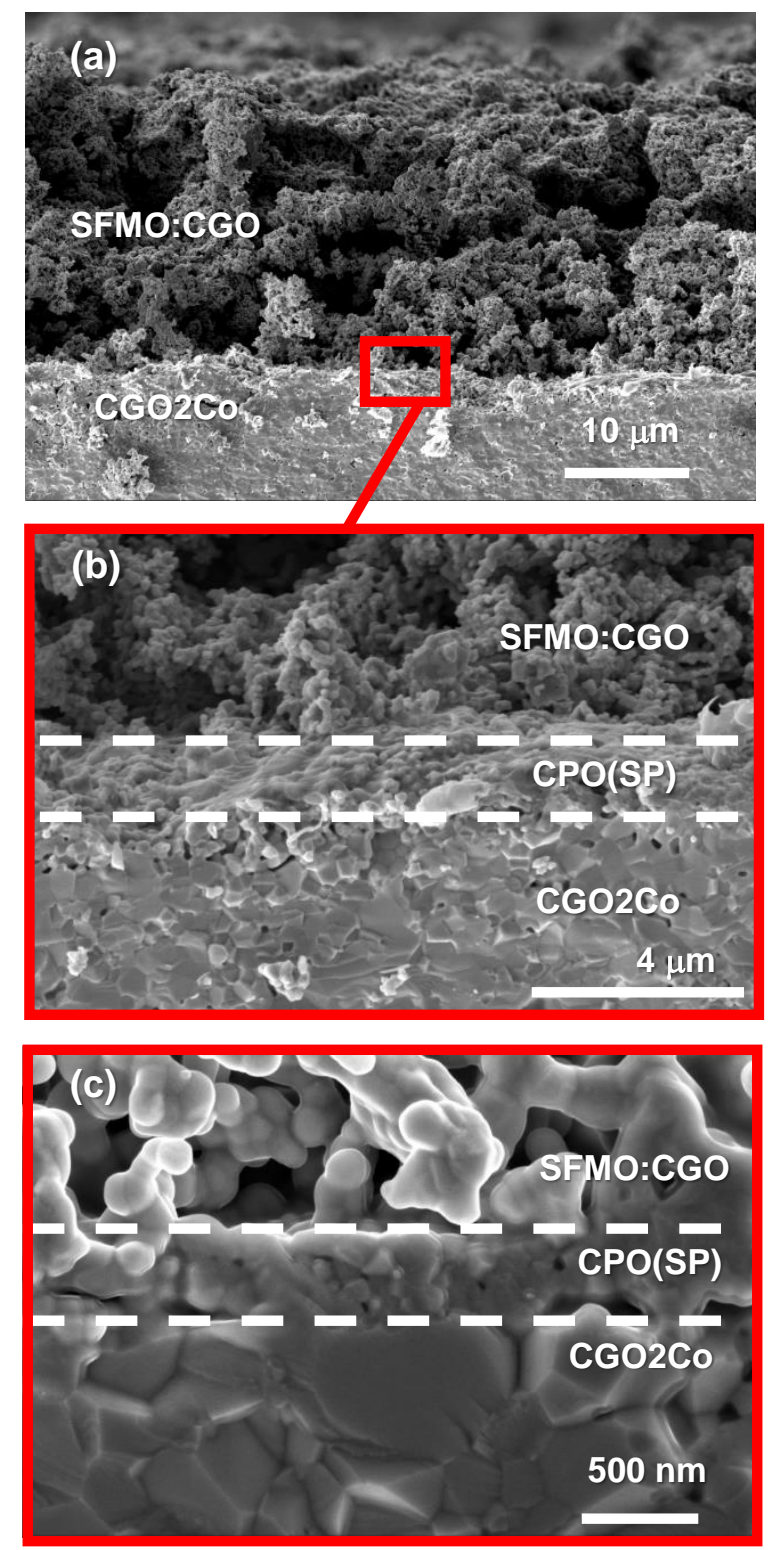

Fig. 5. SEM images of SFM:CGO/CPO(SP)/CGO2Co assemblies: (a) general view; (b) and (c) higher magnification images of the interface between the electrolyte and the air electrode. 


\subsection{Electrochemical performance}

The polarisation resistance of the symmetrical cells was determined by impedance spectroscopy in the range $600-800^{\circ} \mathrm{C}$. A comparison of impedance spectra at 600,650 and $700{ }^{\circ} \mathrm{C}$ of the assemblies with no interlayer and with CGO, CPO and SFM active layers is shown in Fig. 6.
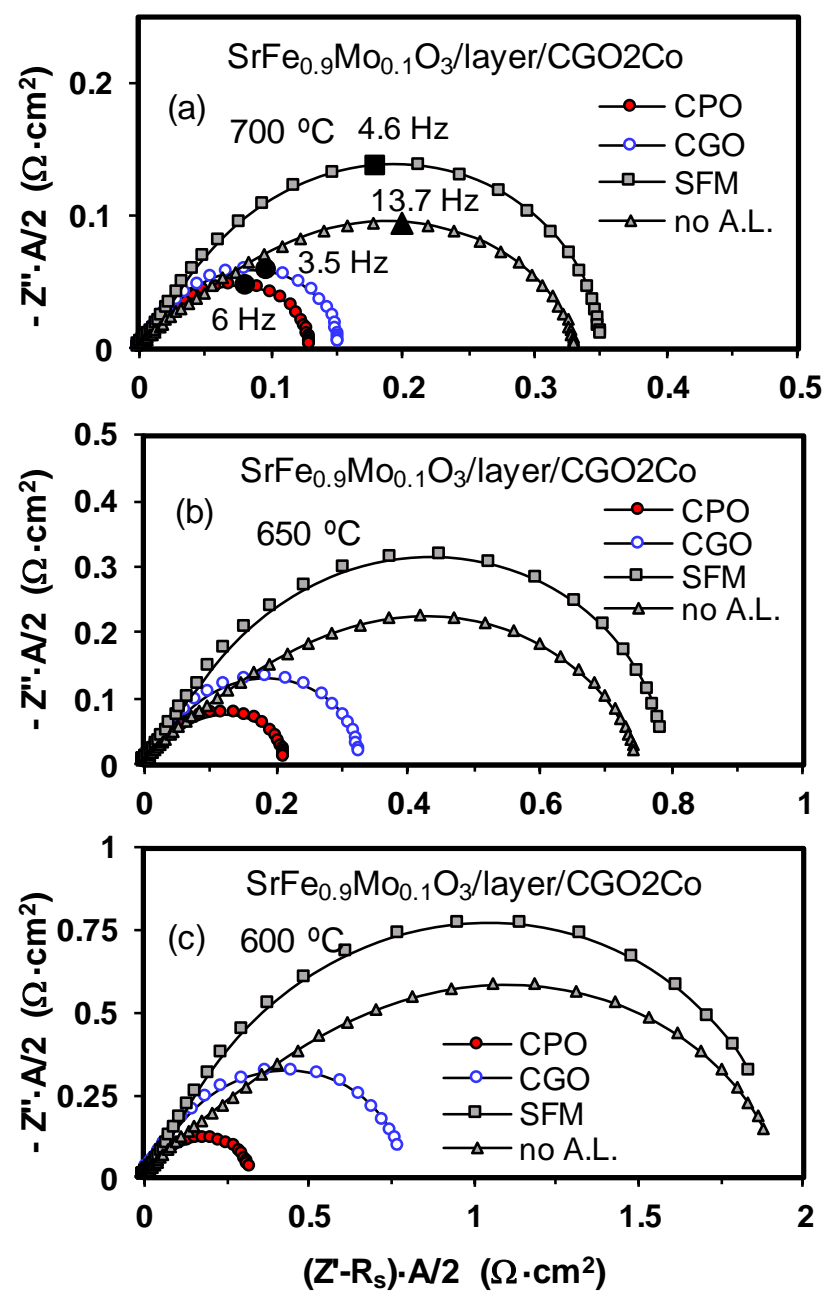

Fig. 6. Comparison of impedance spectra of symmetrical cells with $\mathrm{SrFe}_{0.9} \mathrm{Mo}_{0.1} \mathrm{O}_{3-\delta}$ electrode and different interlayers deposited by spray pyrolysis over CGO2Co electrolyte at (a) $700{ }^{\circ} \mathrm{C}$, (b) $650{ }^{\circ} \mathrm{C}$ and (c) $600{ }^{\circ} \mathrm{C}$. Selected frequencies are indicated in (a) to identify the electrochemical process.

The apparent semicircle contributions present in the spectra in each case are attributable to the electrochemical processes $\left(\mathrm{R}_{\mathrm{p}}\right)$ as confirmed by capacitance values higher than $10^{-}$ 
${ }^{3} \mathrm{~F} \cdot \mathrm{cm}^{-2}$. The spectra also reveal a high-frequency inductive tail associated with the experimental setup, which intercepts the $Z$ ' axis at an impedance value corresponding mainly to the serial electrolyte resistance $\left(\mathrm{R}_{\mathrm{s}}\right)$. Note that for a clearer comparison of the electrochemical processes in Figure 6, the spectra are displaced to the origin of the real axis and negative values of the imaginary axis are not displayed.

The results show that the effect produced by the introduction of the dense SFM interlayer on the total electrochemical polarisation resistance is minimal, as is expected from the similarity in composition of the active layer and electrode. However, a significant decrease of the resistance of the electrode process is observed with CGO and CPO as active layers. In this regard, the introduction of the nanometric dense ceria-based compositions may limit the diffusion of $\mathrm{Sr}$ to the electrolyte, as was previously reported for spray pyrolysed CGO over YSZ electrolyte and LSCF electrode ${ }^{31}$, preventing the formation of a partially insulating surface layer, contributing, at least in part, to the electrochemical improvement. Moreover, distinct behaviours are observed, depending on the temperature range, as confirmed in the Arrhenius representation of the geometrical, area-specific resistance of the electrochemical process presented in Fig. 7(a).
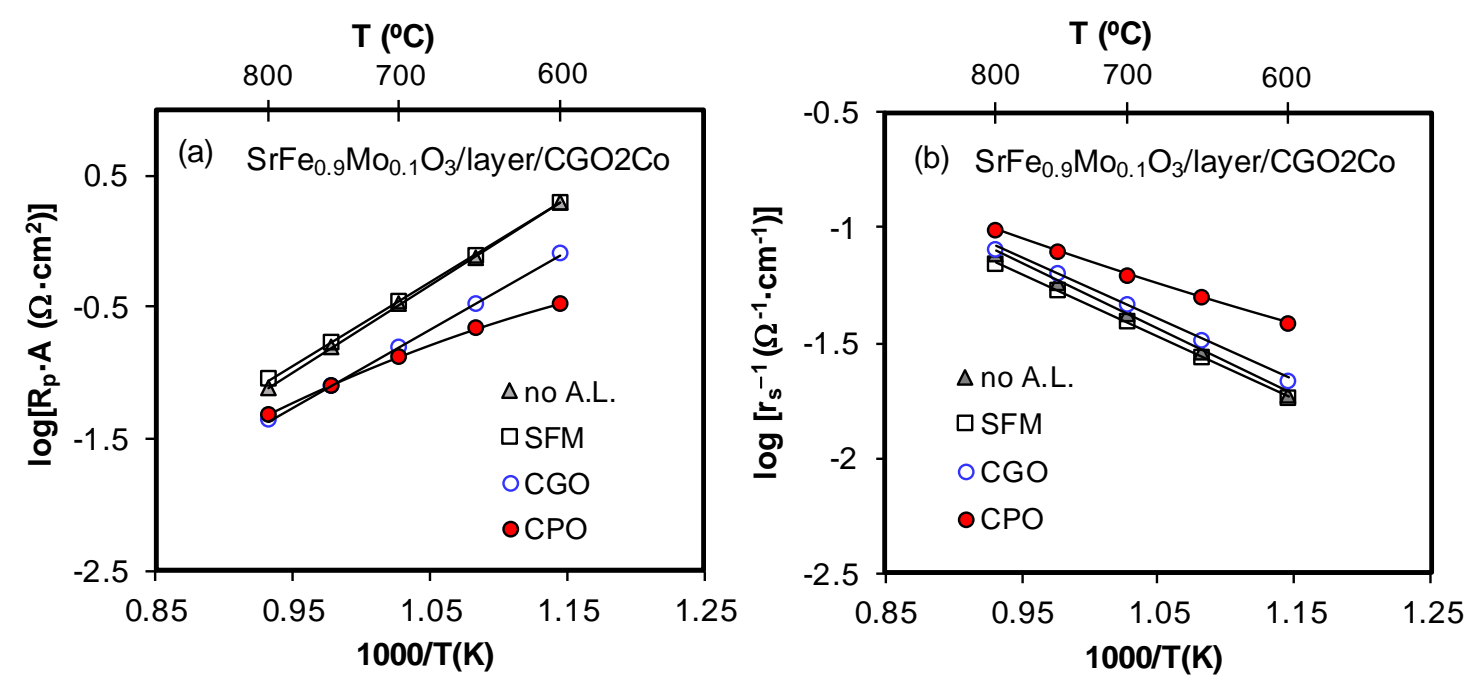

Fig. 7. (a) Arrhenius representation of the area-specific resistance of the electrochemical process, and (b) geometrically normalised series conductance for $\mathrm{SrFe}_{0.9} \mathrm{Mo}_{0.1} \mathrm{O}_{3-\delta}$ electrode with different interlayers.

Similar performances are obtained in the complete temperature range $\left(600-800{ }^{\circ} \mathrm{C}\right)$ for assemblies with and without the SFM interlayer, with respective activation energies of 
1.25 and $1.31 \mathrm{eV}$. In contrast, the CGO interlayer improves performance, with a slightly lower activation energy $(1.17 \mathrm{eV})$ in comparison to the sample without interlayer (Fig. $7(\mathrm{a}))$. In the higher temperature range $\left(700-800^{\circ} \mathrm{C}\right)$, the area-specific resistance of the electrochemical process of the assembly with the CPO interlayer is comparable to that with the CGO interlayer. However, as temperature decreases, the activation energy decreases considerably in comparison to the other compositions $(0.67 \mathrm{eV}$ between 600 $700{ }^{\circ} \mathrm{C}$ ), leading to a much greater improvement of performance in the lower temperature range $\left(600-650^{\circ} \mathrm{C}\right)$. Modification of the activation energy with temperature indicates that the electrochemical-reaction mechanism is altered.

It is generally assumed that, for electronically conducting cathodes, the electrochemical reduction of oxygen may occur along three different paths ${ }^{40}$ : (1) the electrode surface path, including oxygen gas diffusion and adsorption at the electrode surface, followed by diffusion to the three-phase boundary (TPB), where ionization and ionic transfer to the electrolyte takes place; (2) the bulk electrode path, which includes oxygen-gas diffusion, adsorption, incorporation into the cathode, ion transport through the bulk electrode and ionic transfer to the electrolyte; (3) the electrolyte surface path, where the diffusion, adsorption and incorporation of oxygen occurs at the electrolyte surface. The electrochemical reaction is expected to occur in parallel across these three paths, with the fastest step being rate-determining. For typical electrolytes with low electronic conductivity, the electrolyte surface path is limited to the surface very close to the TPB. On the other hand, for mixed-conducting electrodes with high ionic conductivity, the bulk electrode path is expected to be the rate-determining step, because of the very high surface area available for oxygen reduction. This hypothesis is borne out for the assembly without active layer and those with SFM and CGO active layers. In particular, it is observed that the dense SFM interlayer does not modify the electrochemical performance of the porous electrode without an interlayer. The electrode bulk path dominates the electrochemical behaviour and the introduction of a dense layer with similar ionic-electronic characteristics and grain size does not alter the reaction mechanism, including the ionic transfer between the electrode and the electrolyte.

In terms of the series resistance, the experimental value may be approximated as:

$$
R_{S}^{\text {exp }} \approx \rho^{\text {elec }} \frac{L_{e f f}}{A_{\text {eff }}}
$$


where, $L_{\text {eff }}$ and $A_{\text {eff }}$ correspond to the effective values of thickness and transversal area affecting the ohmic transport of ionic species, and $\rho^{\text {elec }}$ is the specific resistivity of the electrolyte. The effective thickness was approximated as that of the electrolyte $\left(L_{\text {eff }} \approx L_{p}\right)$, due to the very low thickness of the active layers $(\sim 0.2-0.4 \mu \mathrm{m})$ in comparison to the thickness of the electrolyte $(\sim 1 \mathrm{~mm})$. On the other hand, the effective area for ionic current transport through the electrolyte is dependent on microstructural parameters, mainly at the exposed surface, which have a significant influence on the active reaction sites. The effective area is represented as a function of the area of the electrodes as $A_{\text {eff }} \approx$ $A_{e l} \cdot f_{a c t}$, where $f_{a c t} \leq 1$ is a factor proportional to the active reaction sites, corresponding to the effective reaction area. We note that, in this approach, $f_{a c t}=1$ corresponds to the whole transversal area of the sample as the effective area, whereas, for typical experimental results, $f_{a c t}<1$. The geometrically-normalised series resistance may be expressed as:

$r_{S}=R_{S}^{e x p} \frac{A_{e l}}{L_{p}} \approx \rho^{e l e c} \frac{1}{f_{a c t}}$

and the geometrically-normalised series conductance as:

$r_{s}^{-1} \approx \sigma^{\text {elect }} f_{\text {act }}$

where $\sigma^{\text {elec }}$ corresponds to the specific ionic conductivity of the electrolyte. The geometrically normalised series conductance, represented in Fig. 7(b), reveals that both the assembly with SFM as active interlayer and that without interlayer exhibit similar values of normalised series conductance, suggesting a similar effective area for the electrochemical reaction, according to Eq. (3). On the other hand, the presence of CGO as interlayer slightly increases the normalised series conductance. This improvement may be associated with a better coupling between the porous electrode and the nanometric interlayer, which should improve the ionic current collection associated with a slightly higher effective area and also the ionic transfer at the electrode/electrolyte interface. This is reflected in the decrease of the geometrical-area-specific resistance of the electrode process, as shown in Fig. 7(a). A greater improvement of the geometrically normalised series conductance is observed at higher temperature for the CPO active interlayer; moreover, on decreasing temperature, the performance of the assembly with the CPO interlayer becomes progressively better than that of the other assemblies (Fig. 7(b)). A schematic diagram of the electrochemical processes occurring at the air electrode for the different assemblies is shown in Figs. 8(a-c). According to previous reports ${ }^{28,41}$, although 
similar values of ionic conductivity are expected for the CGO and CPO components, the mixed $\mathrm{Pr}^{3+}$ and $\mathrm{Pr}^{4+}$ valence states of $\mathrm{CPO}$ offer considerably greater p-type electronic transport. As temperature decreases, the electronic transport number of $\mathrm{CPO}$ increases significantly, due to the reoxidation of $\mathrm{Pr}^{3+}$ to $\mathrm{Pr}^{4+}$, and evolves towards mixed conductivity at intermediate temperatures with high values of ambipolar conductivity ${ }^{28}$. The sites for electrochemical reaction are, thus, highly active at lower temperatures, because the free surface of the CPO interlayer becomes suitable for oxygen reduction (Fig. 8(c)). For the assembly with the CPO interlayer, the low ionic conductivity of the SFM porous component as temperature decreases ${ }^{4}$ is compensated by the high mixedconducting character of $\mathrm{CPO}$, which promotes the extension of the surface path to the active interlayer, thus markedly improving the electrochemical performance (Fig. 7(a)). Moreover, the effective area for ionic transport is considerably improved, which is reflected in a significant enhancement of the geometrically-normalised series conductance (Figs. 7(b) and 8(c)).

(a)

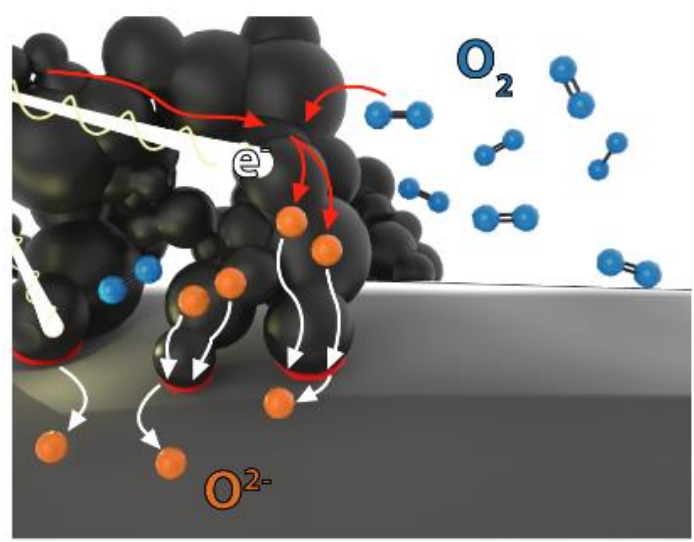

(c)

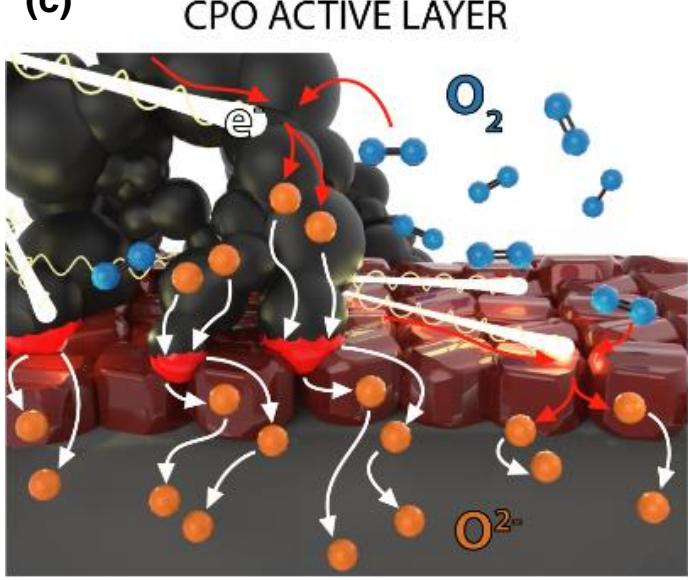

(b)

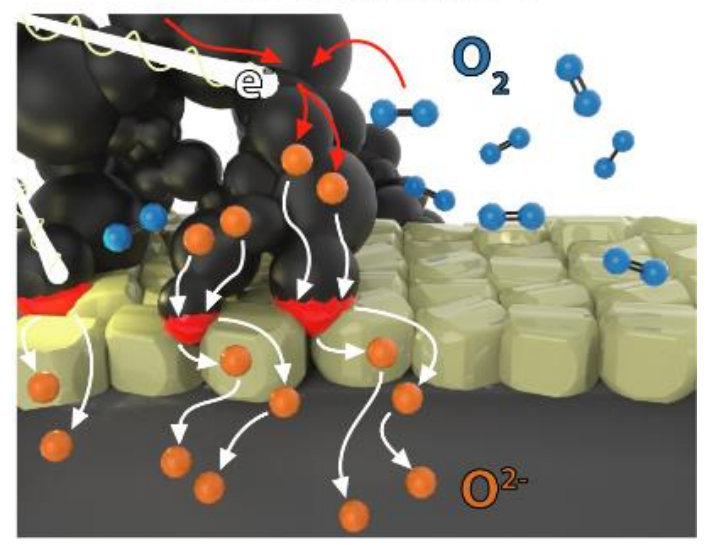

(d)

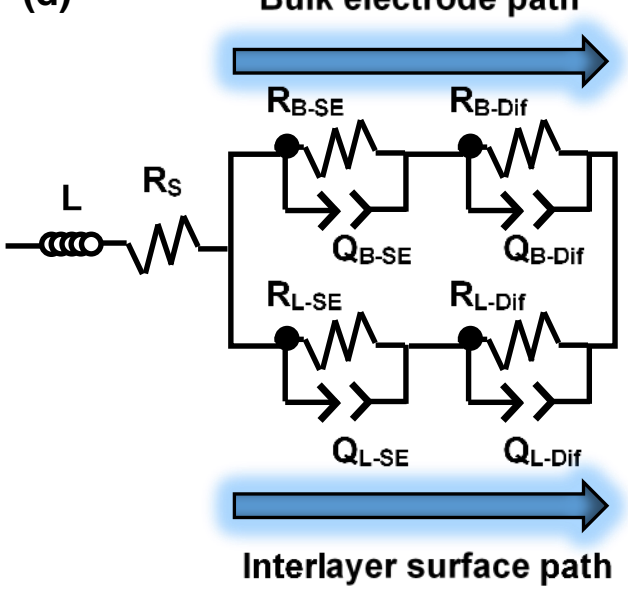


Fig. 8. Schematic diagrams of the electrochemical processes occurring at the air electrode: (a) without interlayer between the electrode and the electrolyte, (b) with CGO interlayer and (c) with CPO interlayer; (d) equivalent circuit simulating the effect of the bulk-electrode path and the active-interlayer surface path for the oxygen electrochemical process.

The parallel contributions corresponding to the bulk electrode path and the activeinterlayer surface path are shown as an equivalent circuit in Fig. 8(d), which was employed for fitting the impedance spectra of the assemblies. Examples of the very good fit between the experimental results and the model for the porous cathode over the CGO2Co electrolyte with and without CPO interlayer at $600{ }^{\circ} \mathrm{C}$ are shown in Fig. 9(a)(d).
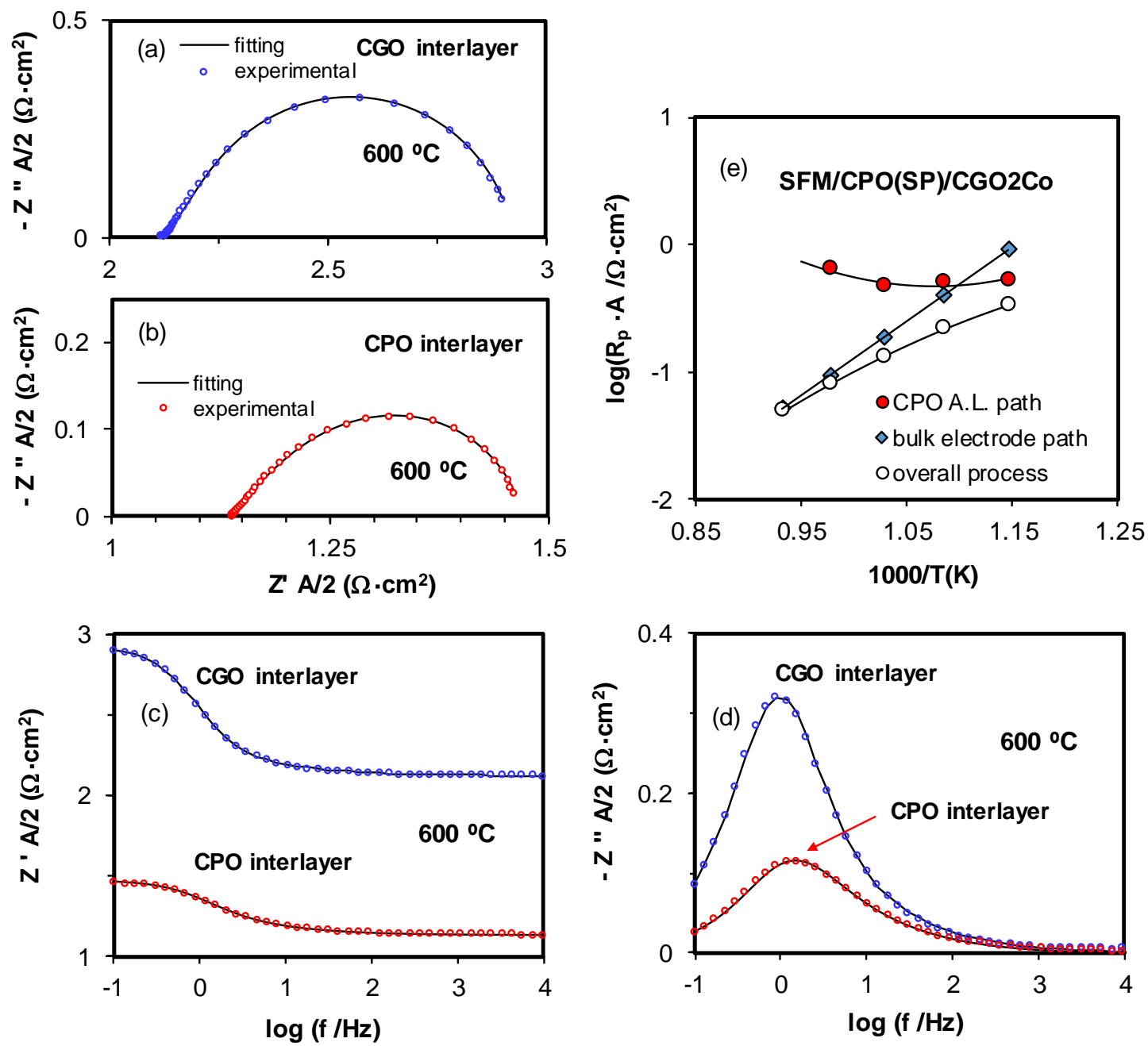

Fig. 9. Experimental and fitting results of impedance spectra at $600{ }^{\circ} \mathrm{C}$ for SFM-CGO porous electrode over CGO2Co electrolyte with (a) CGO interlayer and (b) with CPO 
interlayer; (c) real and (d) imaginary impedance contributions for both assemblies as a function of the frequency; (e) temperature dependence of area-specific resistance corresponding to the bulk electrode path (diamonds), the CPO active interlayer-surface path (closed circles) and the overall assembly (open circles).

The fitting procedure involved removing the active-interlayer surface path for the sample with the CGO interlayer since, in this case, this contribution should be lower in comparison to that of the bulk-electrode path. For the assembly with CPO active layer, the fitting was performed by including the active-interlayer surface path in the equivalent circuit (Fig. 8(d)) and using the fixed values of the bulk-electrode path previously determined in the fitting of the spectra of the assembly with CGO interlayer.

Figure 9(e) shows the temperature dependence of the area specific resistance ascribed to each of these independent paths and the overall effect on cell performance. The results confirm that the parallel path associated with the CPO active interlayer has no apparent effect on the total area-specific resistance at higher temperatures, where the bulk electrode path dominates the electrochemical process. However, it appreciably influences the overall electrochemical performance in the low-temperature range, where the performance of the bulk electrode path is considerably poorer, because the lower ambipolar conductivity of the electrode material ${ }^{4}$ limits the oxygen-surface exchange and oxygen-vacancy diffusion. Combination of the spray pyrolysis methodology for fabrication of nanometric interlayers and good ambipolar conductivity of CPO at lower temperature improves the electrode performance of SFM by an order of magnitude at 600 ${ }^{\circ} \mathrm{C}$ (Fig. 6(c)).

Optimization of the deposition process and the mixed-transport properties of the active interlayer is, thus, a very promising approach for improving the performance of cobaltfree air electrodes in the desirable intermediate temperature range of $600-700{ }^{\circ} \mathrm{C}$. The performance of typical air electrodes is sluggish at this temperature due to poor oxygen exchange at the surface and lower oxide-ion diffusion, both partly attributable to the lower oxygen-vacancy concentration ${ }^{4}$. The good thermal compatibility between the SFM and ceria-based components at lower temperature is a further benefit of the incorporation of the CPO and CGO interlayers. 


\section{Conclusions}

The relatively little explored concept of tailored active interlayers for improving the intermediate temperature $\left(600-700{ }^{\circ} \mathrm{C}\right)$ performance of air electrodes for solid oxide fuel cells and solid oxide electrolyser cells has been examined, employing interlayers of $\mathrm{Ce}_{0.9} \mathrm{Gd}_{0.1} \mathrm{O}_{2-\delta}, \mathrm{Ce}_{0.8} \mathrm{Pr}_{0.2} \mathrm{O}_{2-\delta}$ or $\mathrm{SrFe}_{0.9} \mathrm{Mo}_{0.1} \mathrm{O}_{3-\delta}$ deposited by a spray pyrolysis method (thickness, 200-400 nm) between CGO-based electrolyte and $\mathrm{SrFe}_{0.9} \mathrm{Mo}_{0.1} \mathrm{O}_{3-\delta^{-}}$ $\mathrm{Ce}_{0.9} \mathrm{Gd}_{0.1} \mathrm{O}_{2-\delta}$ composite air electrodes. Significant modifications were observed in the electrochemical performance of assemblies with the different active interlayers. Whereas the $\mathrm{SrFe}_{0.9} \mathrm{Mo}_{0.1} \mathrm{O}_{3-\delta}$ layer of similar composition to the main electrode component did not improve the performance, moderate improvement was achieved for the CGO active layer attributable to better oxide-ionic transfer at the interface, resulting in improved ionic-current collection. The most significant enhancement in performance was achieved for the CPO layer with high mixed ionic-electronic conductivity, which promotes extension of the surface path of the electrochemical reaction to the active interlayer. This enhancement in comparison to the other configurations becomes greater with decreasing temperature due to the concomitant increase in electronic transport number. The concept of nanometric interlayers with tailored mixed-transport properties appears, thus, to be a most promising route to considerably improve the performance of cobalt-free air electrodes in the desired intermediate temperature range for solid oxide cells.

\section{Author information}

Corresponding author

*E-mail: $\underline{\text { dpcoll@icv.csic.es }}$

Notes

The authors declare no competing financial interest.

\section{Acknowledgements}

The authors acknowledge the "Fundación Domingo Martínez" (Ayuda a la Investigación 2017. Área de Materiales: celdas de combustible) and "Ministerio de Ciencia, Innovación y Universidades" (RTI2018-095088-B-I00 and RTI2018-093735-B-I00) for financial support. Collaboration between the research groups was facilitated by the "Red de Excelencia" program (MINECO, MAT2017-090695-REDT). 


\section{References}

(1) Song, Chunshan. Fuel Processing for Low-Temperature and High-Temperature Fuel Cells: Challenges, and Opportunities for Sustainable Development in the 21st Century. Catal. Today 2002, 77 (1-2), 17-49.

(2) Hauch, A.; Ebbesen, S. D.; Jensen, S. H.; Mogensen, M. Highly Efficient High Temperature Electrolysis. J. Mater. Chem. 2008, 18 (20), 2331-2340. https://doi.org/10.1039/b718822f.

(3) Brett, D. J. L.; Atkinson, A.; Brandon, N. P.; Skinner, S. J. Intermediate Temperature Solid Oxide Fuel Cells. Chem. Soc. Rev. 2008, 37 (8), 1568-1578. https://doi.org/10.1039/b612060c.

(4) Zapata-Ramírez, V.; Mather, G. C.; Azcondo, M. T.; Amador, U.; Pérez-Coll, D. Electrical and Electrochemical Properties of the $\mathrm{Sr}(\mathrm{Fe}, \mathrm{Co}, \mathrm{Mo}) \mathrm{O}_{3-\delta}$ System as Air Electrode for Reversible Solid Oxide Cells. J. Power Sources 2019, 437, 226895. https://doi.org/10.1016/j.jpowsour.2019.226895.

(5) Liu, Q.; Dong, X.; Xiao, G.; Zhao, F.; Chen, F. A Novel Electrode Material for Symmetrical SOFCs. Adv. Mater. 2010, 22, 5478-5482. https://doi.org/10.1002/adma.201001044.

(6) dos Santos-Gómez, L.; Compana, J. M.; Bruque, S.; Losilla, E. R.; MarreroLópez, D. Symmetric Electrodes for Solid Oxide Fuel Cells Based on Zr-Doped

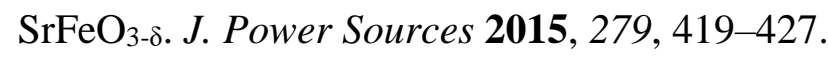
https://doi.org/10.1016/j.jpowsour.2015.01.043.

(7) Adler, S. B. Factors Governing Oxygen Reduction in Solid Oxide Fuel Cell Cathodes. Chem. Rev. 2004, 104 (10), 4791-4843.

(8) Niu, Y.; Liang, F.; Zhou, W.; Sunarso, J.; Zhu, Z.; Shao, Z. A Three-Dimensional Highly Interconnected Composite Oxygen Reduction Reaction Electrocatalyst Prepared from a Core-Shell Precursor. ChemSusChem 2011, 4 (11), 1582-1586. https://doi.org/10.1002/cssc.201100254.

(9) Fan, L.; Zhu, B.; Su, P.-C.; He, C. Nanomaterials and Technologies for Low Temperature Solid Oxide Fuel Cells: Recent Advances, Challenges and Opportunities. Nano Energy 2018, 45, 148-176. 
https://doi.org/10.1016/J.NANOEN.2017.12.044.

(10) Shao, Z.; Zhou, W.; Zhu, Z. Advanced Synthesis of Materials for IntermediateTemperature Solid Oxide Fuel Cells. Prog. Mater. Sci. 2012, 57 (4), 804-874. https://doi.org/10.1016/J.PMATSCI.2011.08.002.

(11) Ding, D.; Li, X.; Lai, S. Y.; Gerdes, K.; Liu, M. Enhancing SOFC Cathode Performance by Surface Modification through Infiltration. Energy Environ. Sci. 2014, 7, 552-575.

(12) Zhang, N.; Li, J.; He, Z.; Sun, K. Preparation and Characterization of Nano-Tube and Nano-Rod Structured $\mathrm{La}_{0.8} \mathrm{Sr}_{0.2} \mathrm{MnO}_{3-8} / \mathrm{Zr}_{0.92} \mathrm{Y}_{0.08} \mathrm{O}_{2}$ Composite Cathodes for Solid Oxide Fuel Cells. Electrochem. commun. 2011, 13 (6), 570-573. https://doi.org/10.1016/J.ELECOM.2011.03.012.

(13) Chen, Y.; Bu, Y.; Zhao, B.; Zhang, Y.; Ding, D.; Hu, R.; Wei, T.; Rainwater, B.; Ding, Y.; Chen, F.; Yang, C.; Liu, J.; Liu, M. A Durable, High-Performance Hollow-Nanofiber Cathode for Intermediate-Temperature Fuel Cells. Nano Energy 2016, 26, 90-99. https://doi.org/10.1016/J.NANOEN.2016.05.001.

(14) Wang, S.; Yoon, J.; Kim, G.; Huang, D.; Wang, H.; Jacobson, A. J. Electrochemical Properties of Nanocrystalline $\mathrm{La}_{0.5} \mathrm{Sr}_{0.5} \mathrm{CoO}_{3-\mathrm{x}}$ Thin Films. Chem. Mater. 2010, 22 (3), 776-782. https://doi.org/10.1021/cm9014139.

(15) la O’, G. J.; Ahn, S.-J.; Crumlin, E.; Orikasa, Y.; Biegalski, M. D.; Christen, H. M.; Shao-Horn, Y. Catalytic Activity Enhancement for Oxygen Reduction on Epitaxial Perovskite Thin Films for Solid-Oxide Fuel Cells. Angew. Chemie Int. Ed. 2010, 49 (31), 5344-5347. https://doi.org/10.1002/anie.201001922.

(16) Januschewsky, J.; Ahrens, M.; Opitz, A.; Kubel, F.; Fleig, J. Optimized $\mathrm{La}_{0.6} \mathrm{Sr}_{0.4} \mathrm{CoO}_{3-\delta}$ Thin-Film Electrodes with Extremely Fast Oxygen-Reduction Kinetics. Adv. Funct. Mater. 2009, 19 (19), 3151-3156.

https://doi.org/10.1002/adfm.200900362.

(17) Fondard, J.; Billard, A.; Bertrand, G.; Briois, P. $\mathrm{Ln}_{2} \mathrm{NiO}_{4+\delta}(\mathrm{Ln}=\mathrm{La}, \mathrm{Pr}, \mathrm{Nd})$ Coatings Deposited by Reactive Magnetron Sputtering as Cathode Material for Intermediate Temperature Solid Oxide Fuel Cell. Vacuum 2018. https://doi.org/10.1016/j.vacuum.2018.03.013. 
(18) Smolyanskiy, E. A.; Linnik, S. A.; Ionov, I. V.; Shipilova, A. V.; Semenov, V. A.; Lauk, A. L.; Solovyev, A. A. Magnetron Sputtered LSC Thin Films for Solid Oxide Fuel Cell Application. In Journal of Physics: Conference Series; Institute of Physics Publishing, 2018; Vol. 1115. https://doi.org/10.1088/17426596/1115/3/032080.

(19) Solovyev, A. A.; Ionov, I. V.; Shipilova, A. V.; Kovalchuk, A. N.; Syrtanov, M. S. Magnetron-Sputtered $\mathrm{La}_{0.6} \mathrm{Sr}_{0.4} \mathrm{Co}_{0.2} \mathrm{Fe}_{0.8} \mathrm{O}_{3}$ Nanocomposite Interlayer for Solid Oxide Fuel Cells. J. Nanoparticle Res. 2017, 19 (3). https://doi.org/10.1007/s11051-017-3791-0.

(20) Chen, Y.; Zhou, W.; Ding, D.; Liu, M.; Ciucci, F.; Tade, M.; Shao, Z. Advances in Cathode Materials for Solid Oxide Fuel Cells: Complex Oxides without Alkaline Earth Metal Elements. Adv. Energy Mater. 2015, 5 (18), 1500537. https://doi.org/10.1002/aenm.201500537.

(21) Rieu, M.; Sayers, R.; Laguna-Bercero, M. A.; Skinner, S. J.; Lenormand, P.; Ansart, F. Investigation of Graded $\mathrm{La}_{2} \mathrm{NiO}_{4+\delta}$ Cathodes to Improve SOFC Electrochemical Performance. J. Electrochem. Soc. 2010, 157 (4), B477. https://doi.org/10.1149/1.3298439.

(22) Sayers, R.; Rieu, M.; Lenormand, P.; Ansart, F.; Kilner, J. A.; Skinner, S. J. Development of Lanthanum Nickelate as a Cathode for Use in Intermediate Temperature Solid Oxide Fuel Cells. Solid State Ionics 2011, 192 (1), 531-534. https://doi.org/10.1016/j.ssi.2010.02.014.

(23) Choi, S.; Kucharczyk, C. J.; Liang, Y.; Zhang, X.; Takeuchi, I.; Ji, H.-I.; Haile, S. M. Exceptional Power Density and Stability at Intermediate Temperatures in Protonic Ceramic Fuel Cells. Nat. Energy 2018, 3 (3), 202-210. https://doi.org/10.1038/s41560-017-0085-9.

(24) dos Santos-Gómez, L.; Porras-Vázquez, J. M.; Martín, F.; Ramos-Barrado, J. R.; Losilla, E. R.; Marrero-López, D. A Novel Multilaminated Composite Cathode for Solid Oxide Fuel Cells. Ceram. Int. 2019, 45 (14), 18124-18127. https://doi.org/10.1016/J.CERAMINT.2019.05.296.

(25) Pérez-Coll, D.; Aguadero, A.; Escudero, M. J.; Núñez, P.; Daza, L. Optimization of the Interface Polarization of the $\mathrm{La}_{2} \mathrm{NiO}_{4}$-Based Cathode Working with the 
$\mathrm{Ce}_{1-\mathrm{X}} \mathrm{Sm}_{\mathrm{x}} \mathrm{O}_{2-\delta}$ Electrolyte System. J. Power Sources 2008, 178 (1), 151-162. https://doi.org/10.1016/j.jpowsour.2007.12.030.

(26) Pérez-Coll, D.; Ruiz-Morales, J. C.; Marrero-López, D.; Núñez, P.; Frade, J. R. Effect of Sintering Additive and Low Temperature on the Electrode Polarization of CGO. J. Alloys Compd. 2009, 467 (1-2), 533-538. https://doi.org/10.1016/j.jallcom.2007.12.039.

(27) Fagg, D.; Kharton, V.; Frade, J. Transport in Ceria Electrolytes Modified with Sintering Aids: Effects on Oxygen Reduction Kinetics. J. Solid State Electrochem. 2004, 8 (9), 618-625. https://doi.org/10.1007/s10008-004-0509-x.

(28) Ramasamy, D.; Nasani, N.; Brandao, A. D.; Pérez-Coll, D.; Fagg, D. P. Enhancing Electrochemical Performance by Control of Transport Properties in Buffer Layers - Solid Oxide Fuel/Electrolyser Cells. Phys. Chem. Chem. Phys. 2015, 17, 11527-11539. https://doi.org/10.1039/C5CP00778J.

(29) Perednis, D. Solid Oxide Fuel Cells with Electrolytes Prepared via Spray Pyrolysis. Solid State Ionics 2004, 166 (3-4), 229-239. https://doi.org/10.1016/j.ssi.2003.11.011.

(30) Evans, A.; Bieberle-Hütter, A.; Rupp, J. L. M.; Gauckler, L. J. Review on Microfabricated Micro-Solid Oxide Fuel Cell Membranes. J. Power Sources 2009, 194 (1), 119-129. https://doi.org/10.1016/j.jpowsour.2009.03.048.

(31) dos Santos-Gómez, L.; Hurtado, J.; Porras-Vázquez, J. M.; Losilla, E. R.; Marrero-López, D. Durability and Performance of CGO Barriers and LSCF Cathode Deposited by Spray-Pyrolysis. J. Eur. Ceram. Soc. 2018, 38 (10), 35183526. https://doi.org/10.1016/J.JEURCERAMSOC.2018.03.024.

(32) Rodríguez-Carvajal, J. Recent Advances in Magnetic Structure Determination by Neutron Powder Diffraction. Phys. B Condens. Matter 1993, 192 (1-2), 55-69. https://doi.org/10.1016/0921-4526(93)90108-I.

(33) Larson, A. C.; von Dreele, R. B. General Structure Analysis System (GSAS); Los Alamos National Laboratory, 1994.

(34) Hodges, J. P.; Short, S.; Jorgensen, J. D.; Xiong, X.; Dabrowski, B.; Mini, S. M.; Kimball, C. W. Evolution of Oxygen-Vacancy Ordered Crystal Structures in the 
Perovskite Series $\mathrm{Sr}_{\mathrm{n}} \mathrm{Fe}_{\mathrm{n}} \mathrm{O}_{3 \mathrm{n}-1}(\mathrm{~N}=2,4,8$, and $\infty)$, and the Relationship to Electronic and Magnetic Properties. J. Solid State Chem. 2000, 151 (2), 190-209. https://doi.org/10.1006/JSSC.1999.8640.

(35) Xiao, G.; Liu, Q.; Wang, S.; Komvokis, V. G.; Amiridis, M. D.; Heyden, A.; Ma, S.; Chen, F. Synthesis and Characterization of Mo-Doped $\mathrm{SrFeO}_{3-\delta}$ as Cathode Materials for Solid Oxide Fuel Cells. J. Power Sources 2012, 202, 63-69. https://doi.org/10.1016/j.jpowsour.2011.11.021.

(36) Fernández-Ropero, A. J.; Porras-Vázquez, J. M.; Cabeza, A.; Slater, P. R.; Marrero-López, D.; Losilla, E. R. High Valence Transition Metal Doped Strontium Ferrites for Electrode Materials in Symmetrical SOFCs. J. Power Sources 2014, 249, 405-413. https://doi.org/10.1016/j.jpowsour.2013.10.118.

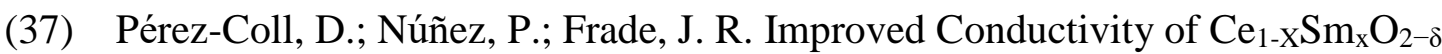
Ceramics with Submicrometer Grain Sizes. J. Electrochem. Soc. 2006, 153 (3), A478. https://doi.org/10.1149/1.2160431.

(38) Izuki, M.; Brito, M. E.; Yamaji, K.; Kishimoto, H.; Cho, D. H.; Shimonosono, T.; Horita, T.; Yokokawa, H. Interfacial Stability and Cation Diffusion across the LSCF/GDC Interface. J. Power Sources 2011, 196, 7232-7236. https://doi.org/10.1016/j.jpowsour.2010.11.013.

(39) Wang, F.; Nishi, M.; Brito, M. E.; Kishimoto, H.; Yamaji, K.; Yokokawa, H.; Horita, T. Sr and Zr Diffusion in LSCF/10GDC/8YSZ Triplets for Solid Oxide Fuel Cells (SOFCs). J. Power Sources 2014, 258, 281-289. https://doi.org/10.1016/j.jpowsour.2014.02.046.

(40) Fleig, J. Solid Oxide Fuel Cell Cathodes: Polarization Mechanisms and Modeling of the Electrochemical Performance. Annu. Rev. Mater. Res. 2003, 33 (1), 361382. https://doi.org/10.1146/annurev.matsci.33.022802.093258.

(41) Fagg, D. P.; Pérez-Coll, D.; Núñez, P.; Frade, J. R.; Shaula, A. L.; Yaremchenko, A. A.; Kharton, V. V. Ceria Based Mixed Conductors with Adjusted Electronic Conductivity in the Bulk and/or along Grain Boundaries. Solid State Ionics 2009, 180 (11-13), 896-899. https://doi.org/10.1016/j.ssi.2009.02.024. 
Table of contents (TOC) graphic

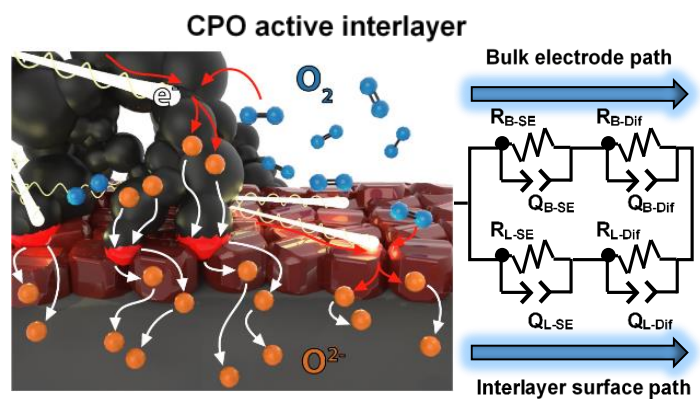

